
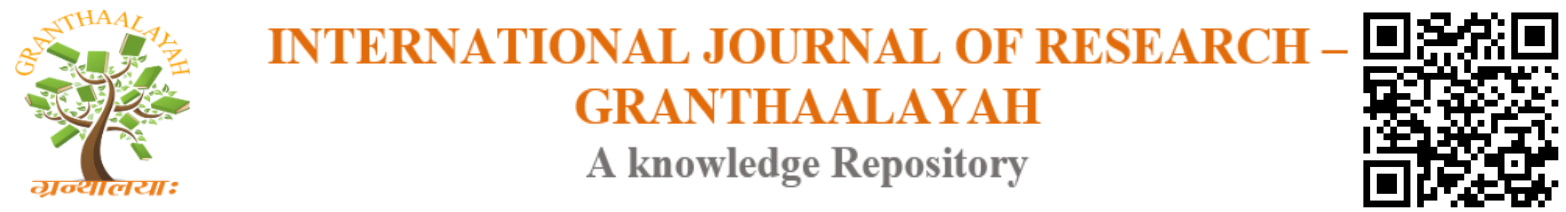

Science

\title{
NEEDLE STICK INJURIES AMONG DENTAL STUDENTS IN ISHIK UNIVERSITY FACULTY OF DENTISTRY AND HAWLER MEDICAL COLLEGE
}

\author{
Mohamed Salim Younus 1, Balen Omer ${ }^{2}$, Aveen Abdulrahman ${ }^{2}$ \\ 1,2 Pediatric department, Faculty of dentistry, Ishik University, Erbil, Iraq
}

\begin{abstract}
Background and objectives: Needle stick injuries pose a high risk to health care workers including dental students. They represent a major risk factor for transmitting blood borne pathogens including hepatitis $\mathrm{B}$ virus, hepatitis $\mathrm{C}$ virus and human immunodeficiency virus. Needles of syringes are the most commonly identified sharp object causing the injuries. Therefore, this study conducted to determine the prevalence of needle stick injuries among dental students in Ishik university facualty of dentistry and Hawler medical college. Aim and objectives of the study: The study aimed were to: 1 . Find out the prevalence of NSI among dental student in Erbil cityIraq. 2. The percentage of dental students that had taken Hep B vaccine. 3. Study the knowledge of dental students regarding NSI.
\end{abstract}

Subjects and method: The study was a cross sectional in nature, 114 students from Ishik University and Hawler Medical University Collage of Dentistry and data collections were done from the 1st of Dec till 2 of Feb 2018. Later on, data analysis and writing the thesis completed in May up to June, 2018. A questionnaire was completed through direct interview of the study students to measure their knowledge and practice about needle sticks injuries. All the obtained information including prevalence of needle sticks injuries, within previous 12 months, time of injury, and training on needle stick injury, knowledge, practice and attitude about needle sticks was then analyzed using statistical package for the social science software version 21.

Results: The mean age of the participants was 22 . The results of the study demonstrated that the prevalence of needle stick injury during past 12 months among dental students was 47,4\%. Needle stick injury happened after using the needle in $35.2 \%$, while in re-capping the needle occur in $27,8 \%$ and around $41.2 \%$ of the samples have precautions regarding NSI.

Conclusion: The dental student had taken hepatitis B vaccine in a high percentage, while the prevalence of NSI was high and male showed higher prevalence than female. Training course regarding the precaution and management of NSI may need to be added to the curriculum of dental students.

Keywords: Needle Stick Injuries; Dental Students; Hepatitis; Erbil City.

Cite This Article: Mohamed Salim Younus, Balen Omer, and Aveen Abdulrahman. (2019). "NEEDLE STICK INJURIES AMONG DENTAL STUDENTS IN ISHIK UNIVERSITY 
FACULTY OF DENTISTRY AND HAWLER MEDICAL COLLEGE.” International Journal of Research - Granthaalayah, 7(4), 1-13. https://doi.org/10.29121/granthaalayah.v7.i4.2019.930.

\section{Introduction}

The World Health Organization (WHO) appraises that 16 billion Needle stick injury (NSI) were managed every year in creating nations with a dominant part $(90-95 \%)$ of these injures given for medical purposes [1].

The risk of injuries by sharps were usually faced at various fronts including student immunization, adequate safety-based clinical induction and training, dissemination of safety protocols and guidelines and finally introduction of safer technologies that contribute to elimination or at least significant reduction of such incidents [2].

Dental students were trained at various dental departments during the third, fourth and fifth years of their 5-year course with maximum clinical load during their fourth and fifth years as they complete a significant number of their clinical cases requirements, and thus they were considered to be at a higher risk of such hazards as compared with their medical counterparts who rarely undertake exposure-prone techniques as undergraduates [3]. Little information regarding needle injury among dental students especially in Iraq and Kurdistan, so it was decided to conduct this study.

NSI were considered to be one of the most common reason of exposure to serious and fatal diseases among health care worker $(\mathrm{HCW})$ and the most hazard factor for transmitting blood borne pathogens (BBPs). All HCW who perform invasive techniques with sharp instruments were in danger for NSI [4]. The injury was mainly related to instruments cleaning, needles recapping and giving anesthesia. However, a few needle types and other sharp devices were related with the majority of these injures. In such manner, syringes are the most usually recognized sharp object causing this type of injury [5].

\subsection{Definition of Needle Stick Injuries}

Generally, an NSI was define as an injury sustained by an individual due to a potentially contaminated needle, NSI were typically occur in the HCW and dentist environment, when drawing blood, administrating an intravenous or intramuscular medication, the needle can slip and injury the HCW. This may transmit pathogens from the source individual to the receiver. These injuries generally happen during needle recapping and because of inability to put utilized needles in approved sharps holders. Mostly NSI cause just minor trauma and bleeding, in any case, even without trauma and bleeding the danger of contamination and infection remains. Thus, a NSI may represent a hazard for a patient if the injured health professional carriers HBV, HCV or HIV. NSI were not limited to the medical group [6].

Also, dental healthcare workers (DCHWs) were at a high risk of injuries by sharps and, of these, the most common were due to needle sticks. Needle stick injuries (NSIs) may be sustained during injecting local anesthesia recapping or disposal of the needle and syringe. Thus 'commonly these hollow bores are already contaminated causing dirty NSIs with the attendant significant risks of 
work acquired infections [7]. Dental students were trained on many departments during the last 3years of their 5-year course with high clinical load as they complete their clinical requirements, so they considered at a higher risk of such hazards. On other hand, the dental nurse students receive a foundation training course which leads to registerable qualifications. The nurse students prepare and maintain environments, instruments, and equipment for clinical dental procedures. They also provide chair-side support during the various aspects of dental care [8].

Mostly NSI characterized as damage managed by a person because of a possibly polluted needle point [9].The Centers for Disease Control and Prevention (CDC) characterize a NSI as an entering cut injury from a needle (or other sharp protest) that may bring about exposure to blood or other body liquid contaminations [10].

\subsection{Dental Syringe}

It is the vehicle whereby the contents of the anesthetic cartridge are delivered through the needle to the patient. American Dental Association criteria for acceptance of local anesthetic syringes include the following [11]:

1) They must be durable and able to withstand repeated sterilization without damage (If the unit is disposable, it should be packaged in a sterile container).

2) They should be capable of accepting a wide variety of cartridges and needles of different manufacture, also it should permit repeated use.

3) They should be inexpensive, self-contained, lightweight, and simple to use with one hand.

4) They should provide effective aspiration so that blood may be easily observed in the cartridge.

\subsubsection{Syringe Types Available in Dentistry}

1) Non disposable syringes: a- Breech-loading, metallic, cartridge-type, aspirating. bBreech-loading, plastic, cartridge-type, aspirating. c- Breech-loading, metallic, cartridgetype, self-aspirating. d- Pressure syringe for periodontal ligament injection. e- Jet injector ("needle-less" syringe).

2) Disposable syringes.

3) Safety" syringes.

4) Computer-controlled local anesthetic delivery systems [12].

\subsection{Determinants of needle stick injuries}

The determinants of NSIs include the following:

1) Recapping of needles after utilize.

2) Overuse of injections and pointless sharps.

3) Lack of access to sharps disposal containers immediately after injection.

4) Passing instruments from hand to hand throw the working theater.

5) Lack of supplies: disposable syringes, safer needles devices, and sharps disposal containers.

6) Inadequate or short staffing.

7) Lack of awareness of hazards and lack of training. 
8) Lack of awareness of hazards and lack of training [13].

When the needle has been utilized in a patient, potentially infectious body material can be transferred to the HCW who was injured while performing their duty as reported by the National Institute for Occupational Safety and Health [14]. Five activities were related to NSIs. These include the following: 1) Disposing of needles, including the accumulation and transfer of materials utilized during patient care procedure; (2) administration of injections; (3) blood drawing; (4) recapping of needles and (5) handling of trash and dirty linens [15].

\subsection{The Prevalence of Needle Stick Injuries and Blood Borne Pathogens}

The annual number of NSIs and the prevalence of blood borne pathogens in the developing world community were assessed to be $40 \%$ for both HBV and HBC infections and $2.5 \%$ for the HIV infections among HCWs [13]. Investigation among American surgeons indicates that most of them were experienced at least one NSI during their training [4]. In Egypt around $61 \%$ and $71.4 \%$ of the doctors and dental specialists experienced at least one needle stick during their training [16]. While in India $36 \%$ of HCWs had a history of NSI [17].

\subsection{Immediate Action Post-Exposure to Needle Stick Injuries and Blood Borne Pathogens}

All HCWs should immediately post-exposure to NSIs, blood or other body substances do the following:

1) Wash the exposed site, cuts or puncture of the skin or intact skin with soap and water.

2) Inform the supervisor or an appropriate person to ensure that necessary further action is undertaken.

3) Follow the institution/hospital Post Exposure Prophylaxis (PEP) procedure on exposure to NSIs and/or BBPs [2].

\subsection{The Guidelines for Management of Exposure to Needle Stick Injuries and Blood Borne Pathogens}

If you experienced a needle stick or sharps injury or were exposed to the blood or other body fluid of a patient during the course of your work, immediately follow these steps:

1) Immediately allow the entry wound to bleed freely (1 to 2 minutes) and wash with soap and running water. Disinfect the wound with disinfectant available in your hospitals /institutions, flush splashes to the nose, mouth, or skin with water.

2) Report the incident to your immediate supervisor.

3) If possible have blood taken from the patient immediately, after obtaining written consent. Arrangements for this may be made with the registrar on call for Internal Medicine. However, do not waste time you can always go back to the patient to draw blood.

4) Should the patient refuse to have blood taken, if the source of contamination is untraceable (unknown needle in rubbish bin), or if there is any suspicion that the patient may be in the window period, the patient must be regarded as HIV positive. 
5) Babies of HIV positive mothers must always be regarded as sero-positive. At present it is not possible to eliminate HIV infection in a baby with any certainty before the age of 18 months.

6) HCW should be tested immediately and confidentiality for HIV, HBV and HCV infection.

7) Get post exposure prophylaxis

8) Document the exposure details in full.

9) Get confidential follow up, post exposure testing at six weeks, three months and six months and depending at the risk, at one year.

10) Receive monitoring and follow up of PEP $[2,18]$.

\subsection{Further Management}

After an NSI, certain strategies must be taken to limit the danger of contamination for the recipient. The affected area should be rinsed and washed thoroughly with soap and water; the practice to "milk out" more blood is controversial and not recommended by the CDC [19]. In order for baseline studies Lab tests of the recipient are obtained: HIV, acute hepatitis panel (HAV IgM, HBsAg, HB core IgM, HCV) and for immunized individuals HB surface antibody. Unless already known, determination of the infectious status of the source done by checking for HBs AG, anti$\mathrm{HCV}$, and HIV antibody. Unless the source is known to be negative for HBV, HCV, and HIV postexposure prophylaxis (PEP) ought to be started, preferably inside one hour of the damage; normally this is done in the emergency department or the occupational health office [20]. Guidelines for PEP have been updated over recent years in view of the introduction of new drugs, and protocols may differ somewhat between countries.

\subsection{Prevention}

Steps of prevention can be taken at several levels and include reduce or elimination of use of sharps as much as possible, engineering controls (i.e., needles or syringes with safety devices), control of administration including training and provision of adequate resources, and work practice controls; the latter may include using instruments to grasp needles and avoid use of fingers, load scalpels, and sharp instruments should not be passing by hand to hand also preparing of medications especially removing cap. Removing cap from a needle generally causes NSI. The cap can be removed by several way from the needle but the most ideal and safest way to remove it is by grasping the syringe carefully and by the thumb guiding the needle cap and the pointing finger. Then gently push the cap away from the syringe to detach the cap from the hub. Do not use the other hand as it increases the likeliness to have the syringe to rebound [21]. The development of safety needles and needle removers are included in engineering advances. The adherences to "notouch" protocols that remove direct contact with needles in their use and disposal greatly reduce the risk of injury. In the surgical setting, like in abdominal operations, 54\%. Of NSI reduced by blunt-tip suture needles. The American College of Surgeons (ACS) has endorsed the adoption of blunt-tip suture needles for suturing fascia [22].

Some countries have enacted legislation to protect HCW. In the US, in 2000 the Needle stick Safety Act was signed and in 2001 Blood borne Pathogens Standard. These regulations mandate the use of safety devices and needle-removers with any sharps or needles [23]. Significant declines in the incidence of NSI can be achieved by increasing scientific data indicating that the 
introduction of safer needle devices especially in combination with a comprehensive educational and training process. In this regard, care during cleaning of instruments, better training, avoiding hazardous practices such as recapping needles and development of safer needles may prevent or reduce the incidence of injury and disease [24].

\subsection{Needle Stick Injuries Self-Reporting}

All NSIs should be reported, benefits to the HCW include counseling, access to PEP, and the possibility of secondary transmission to patients and sexual partners is removed. There are also legal aspects for the reporting, thus event should be documented in order to establish a causal link between exposure and a subsequent complication claimed by the HCW. A lack of reporting may lead to denial of such claims, and the HCW will not be compensated [4].

\subsection{Aim and Objectives of the Study}

The study aimed were to:

1) Find out the prevalence of NSI among dental student in Erbil city-Iraq.

2) The percentage of dental students that had taken Hep B vaccine. 3-Study the knowledge of dental students regarding NSI.

\section{Materials and Methods}

\subsection{Study Setting}

This study was carried out at the Faculties of dentistry Ishik University and Hawler Medical University in Erbil-city. The dentistry department was open daily (except for public holiday, friday and saturday), and on average 100-200 patients were seen on daily bases. The majority of dentistry staff was adults with an age range from 2050 years old.

\subsection{Study Design and Duration}

A cross-sectional study was designed to achieve the aim and objectives of the study among dentistry students. Preparation of questionnaires, formal consent paper from Ishik University and Hawler Medical University Collage of Dentistry and data collections were done from the 1st of Dec till 2 of Feb 2018. Later on, data analysis and writing the thesis completed in May up to June, 2018.

\subsection{Study Sample and Sample Size}

All fifth grade students who were working in the dentistry department of Ishik University and Hawler Medical University were invited to participate in this study, the total number of students were 130 participants, however only 125 were agreed to participate during the period of data collection of two months. 


\subsection{Inclusion Criteria}

All students in fifth grade who were working in the dentistry department and who were agreed to participate in the study.

\subsection{Exclusion Criteria}

Around 5 students were excluded from the study because they refused to participate.

\subsection{Ethical Considerations}

The study protocol was approved by research committee of the executive office of Faculty of Dentistry in Ishik University before starting the research. After that a verbal consent was taken from all participants prior to participation in the study and before filling up the questionnaire form by the researcher. The purpose of the study was carefully explained to each participant, with assurance of the privacy and confidentiality of collected data and information was kept by researcher and that no name was mentioned. All the participants were given the right whether to participate or not in the study and possibly consult others before giving verbal consent. All selected participants were cooperative and agreed to participate in the study.

\subsection{Data Collection}

\subsubsection{Interviewing}

During the interview, the English language was used by researcher. The answers were written in English on the questionnaires paper. The questionnaire was filled by interviewer. All personal information was recorded without the participant's name specified. Dentistry student's participation was voluntary, and respondents' anonymity was maintained.

\subsubsection{Questionnaire}

An interviewer questionnaire was designed by the researcher and reviewed by supervisor. A questionnaire was designed using appropriate internet resources and databases. Ultimately, all the variables included in previous studies, including new variables were designed in the questionnaire which consisted of two parts: the first section included personal information such as age, gender and marital status. The second part was related to previous needle stick in the past one year, time of injury, personal protective procedures, immunization and vaccine against serious infectious diseases.

\subsection{Statistical Analysis}

Data were analyzed using the Statistical Package for Social Sciences (SPSS, version 22). Chi square test of association was used to compare between proportions. A p value of $\leq 0.05$ was considered statistically significant. 


\section{Result}

\subsection{The Sample}

The sample consist of 114 dental students from Ishik University and Hawler medical University collage of dentistry, 54 of the sample were males $(47.4 \%)$ and 60 were females $(52.6 \%)$. The distribution of sample according to gender was summarized in Table (1). The sample distribution according to marital status showed that $86 \%$ of sample were single and $13.2 \%$ were married while less than $1 \%$ was divorced, as shown in Table (2). The result showed that $86 \%$ of dental students had taken Hep B vaccine while only $14 \%$ of the students, had not taken the vaccine, as shown in Table (3).

Table 1: Distribution of sample by gender

\begin{tabular}{|l|l|l|}
\hline Gender & Frequency & Percent \\
\hline Male & 54 & $47.4 \%$ \\
\hline Female & 60 & $52.6 \%$ \\
\hline Total & 114 & $100.0 \%$ \\
\hline
\end{tabular}

Table 2: Distribution of students by marital state

\begin{tabular}{|l|l|l|}
\hline Marital Status & Frequency & Percent \\
\hline Single & 98 & $86.0 \%$ \\
\hline Married & 15 & $13.2 \%$ \\
\hline Divorced & 1 & $.9 \%$ \\
\hline Total & 114 & $100.0 \%$ \\
\hline
\end{tabular}

Table 3: Distribution of students by hepatitis B vaccination

\begin{tabular}{|l|l|l|}
\hline Hepatitis B vaccine & Frequency & Percent \\
\hline Yes & 98 & $86.0 \%$ \\
\hline No & 16 & $14.0 \%$ \\
\hline Total & 114 & $100.0 \%$ \\
\hline
\end{tabular}

\subsection{The Prevalence of NSI Among Dental Students}

The result showed that $47.4 \%$ of samples were exposed to NSI while $52.6 \%$ not exposed, and male was higher than female regarding NSI with no significant difference, as shown in Table (4). While for the distribution of sample according to the time of exposure showed that $24.1 \%$ of student exposed during using of the needle and $35.2 \%$ exposed after using the needle while $27.8 \%$ during recapping the needle while $13.0 \%$ of students exposed during discarding the needle, as shown in Table (5).

Table 4: Distribution of samples according to NSI Exposure

\begin{tabular}{|l|l|l|l|l|}
\hline NSI Exposure & Male & Female & Percent & P-value \\
\hline Exposed & $50 \%$ & $45 \%$ & $\mathbf{4 7 . 4 \%}$ & $\mathbf{0 . 5 8}$ \\
\hline Not exposed & $50 \%$ & $\mathbf{5 5 \%}$ & $\mathbf{5 2 . 6 \%}$ & $\mathbf{0 . 3 6}$ \\
\hline Total & $\mathbf{1 0 0 \%}$ & $\mathbf{1 0 0 \%}$ & $\mathbf{1 0 0 . 0 \%}$ & \\
\hline
\end{tabular}


Table 5: Distribution of samples according to the time of NSI

\begin{tabular}{|l|l|l|}
\hline NSI times & Frequency & Percent \\
\hline While using needle & 13 & $24.1 \%$ \\
\hline After using needle & 19 & $35.2 \%$ \\
\hline While recapping needle & 15 & $27.8 \%$ \\
\hline While discarding the needle & 7 & $13.0 \%$ \\
\hline Total & 54 & $100.0 \%$ \\
\hline
\end{tabular}

\subsection{Action Performed After NS}

The result showed that $85.2 \%$ of students had performed an action such as washing the wound with soap and water after the exposure to NSI while $14.8 \%$ not performed anything after the exposure, as shown in Table (6). The result also showed that $34.8 \%$ of students had post exposure immunization after NSI while $65.2 \%$ not immunized after NSI, male founded to be more PEP than female with no significant differences as shown in Table (7).

Table 6: Distribution of samples according to the action performed

\begin{tabular}{|l|l|l|}
\hline Action Performed & Frequency & Percent \\
\hline Yes & 46 & $85.2 \%$ \\
\hline No & 8 & $14.8 \%$ \\
\hline Total & 54 & $100.0 \%$ \\
\hline
\end{tabular}

Table 7: Distribution of student according to immunization after NSI

\begin{tabular}{|l|l|l|l|l|}
\hline Immunization after NSI & Male & Female & Percent & P-value \\
\hline Yes & $37 \%$ & $29.6 \%$ & $34.8 \%$ & 0.47 \\
\hline No & $63 \%$ & $70.4 \%$ & $65.2 \%$ & 0.61 \\
\hline Total & $100.0 \%$ & $100 \%$ & $100.0 \%$ & \\
\hline
\end{tabular}

\subsection{The presence of sharp box in the clinic}

The result showed that $41.2 \%$ of samples had a sharp box in the clinic while $58.8 \%$ said that there is no sharp box in their clinic, as shown in Table (8). The distribution of the samples according to receiving any precaution regarding NSI showed that $62.3 \%$ of samples had received the precaution regarding NSI and $37.7 \%$ had not received any precaution, as shown in Table (9).

Table 8: Distribution of having sharp box

\begin{tabular}{|l|l|l|}
\hline Having Sharp Container & Frequency & Percent \\
\hline Yes & 47 & $41.2 \%$ \\
\hline No & 67 & $58.8 \%$ \\
\hline Total & 114 & $100.0 \%$ \\
\hline
\end{tabular}

Table 9: Distribution of receiving precaution regarding NSI

\begin{tabular}{|l|l|l|}
\hline Receiving precaution & Frequency & Percent \\
\hline Yes & 71 & $62.3 \%$ \\
\hline No & 43 & $37.7 \%$ \\
\hline Total & 114 & 100.0 \\
\hline
\end{tabular}




\section{Discussion}

NSI represent as one of the major risk factor for transmitting blood borne pathogens including hepatitis $B$ virus, hepatitis $C$ virus and human immunodeficiency virus. The sample consisted of 114 dental students from ishik university faculty of dentistry and hawler medical college faculty of dentistry, those students divided into $47.4 \%$ male and $52.6 \%$ female. For the marital status of the sample, $86 \%$ were single, $13.2 \%$ were married and less than $1 \%$ was divorced.

\subsection{Hepatitis $B$ vaccine}

The result showed that $86 \%$ of sample had taken the vaccine, while only $14 \%$ did not take the vaccine, similar result was also founded by [25] which showed that the students who vaccinated were $84.1 \%$ and who were not vaccinated $15.9 \%$. While higher result recorded by [26; 27] that showed that the percentage of vaccinated participants were $92.8 \%$ and $93.3 \%$ respectively. The high prevalence of hepatitis B vaccine maybe due to high level of education of students and staff of collage.

\subsection{The Prevalence of NSI}

The prevalence of NSI was founded to be $47.4 \%$ similar result was founded by [28] which had showed that $45 \%$ of participants had NSI. While low prevalence founded by many studies [25; 29] Kumar S 2016) that showed the prevalence of NSI to be $31.5 \%$, 35\% respectively. Higher prevalence was founded by $[30 ; 31 ; 32]$ which had showed the prevalence of NSI to be $(79.5 \%$ , $67.9 \%$ 64\%) respectively. The higher prevalence of NSI may be attributed to the less experience and precaution of those student regarding NSI. In male the prevalence of NSI was showed to be $50 \%$ which was non significantly higher than that in female $45 \%$, similar result was also founded by [33] where they showed the prevalence of NSI to be $36.7 \%$ in male and $34.2 \%$ in female. This result may be due to that the female are more careful than male and the male are more.

\subsection{When NSI Occur}

The result showed that the most common time of NSI was after using the needle $35.2 \%$ of sample, while less time of NSI was while discarding the needle 13\%. Different results were founded by a study [34] in which $36 \%$ of the incidents occurred when administering local anesthesia, 18\% when recapping needles, while other study [30] showed that most of the injuries occurred during recapping (34.0\%). This result may due to less experience of students and stress of the student to finish their requirement.

\subsection{Action performed after NSI}

The result showed that $85.2 \%$ of students performed an action such as washing of wound by water or antiseptic after NSI while another study showed that less than $27 \%$ performed washing of wound after NSI [34]. The high percentage may be due to high knowledge of student and precaution of student and the low level may be due to low value of education on these area, 


\subsection{Immunization Regarding NSI}

This study showed that $34.8 \%$ of student did immunization after NSI, $37 \%$ of them were male which was non significantly more than female $29 \%$, this result differ than that founded by other [33] which showed that only $3 \%$ had taken post exposure prophylaxis. The low result may be due to the less level of knowledge in this field.

\subsection{Sharp Box}

According to the study $42 \%$ of students reported that they had sharp box in the clinic, another research showed that $57.2 \%$ of students reported that they had sharp box in the clinic [32].

\subsection{Precaution Regarding NSI}

The results showed that $62.3 \%$ had knowledge regarding NSI and this was near to result that found that only 58\% had knowledge regarding NSI [33]. Study reported that $62 \%$ had worn gloves during the procedure [35], difference result founded by other [36] were they showed that only $29 \%$ had knowledge about post exposure prophylaxis.

\section{Conclusion and Suggestion}

\subsection{Conclusion}

1) Most of dental student had taken hepatitis B vaccine.

2) Higher prevalence of NSI among dental students.

3) Male showed higher prevalence of NSI than female.

4) The most common time of NSI after using the needle.

5) Most of the student wash the wound after NSI.

6) Nearly one third of the student had taken PEP after NSI.

7) More than half of student didn't know that there was a sharp box in the dental clinic.

\subsection{Suggestion}

1) Research regarding dentist and dental staff with more sample size may give more informative details.

2) Adding more variable like experience specialty and load of work may give us more information regarding the susceptibility regarding NSI.

3) Training course regarding the precaution and management of NSI need to be added to the curriculum of dental students.

\section{References}

[1] World Health Organisation. WHO Report: Reducing risks, Promoting healthy life. WHO, Geneva, 2002.

[2] Centers for Disease Control \& Prevention (CDC). Updated U.S. Public Health Service Guidelines for the Management of Occupational Exposures to HBV, HCV, and HIV and recommendations for post exposure prophylaxis. Morbidity and Mortality Weekly Report, 2008. 50--RR-11. 
[3] Center for Disease Control and Prevention (2013) Infection Control; what is the risk of infection after an occupational exposure?

[4] Makary MA, Al-Attar A, Holzmueller CG, Sexton JB, Syin D, Gilson MM, et al. Needle stick injuries among surgeons in training. The New England journal of medicine 2007: 356, 2693-2699.

[5] Genel M. Preventing needle stick injuries in health care settings. Reports of council on scientific affairs. 2000.430; 99.

[6] Gebhart Fred. "EPA issues new guidelines for sharps disposal". Drug Topics. 22, 2004;148: 69.

[7] Cardo D M, Culver D H, Ciesielski C A, Srivastava P U, Marcus R, Abiteboul D, Heptonstall J, Ippolito G, Lot F, Mckibben P S \& Bell D. A casecontrol study of HIV seroconversion in health care workers after percutaneous exposure. Centers for Disease Control and Prevention Needlestick Surveillance Group. N Engl J Med, 1997. 337, 1485-90.

[8] Do A N, Ciesielski C A, Metler R P, Hammett T A, Li J \& Fleming P L. Occupationally acquired human immunodeficiency virus (HIV) infection: national case surveillance data during 20 years of the HIV epidemic in the United States. Infect Control Hosp Epidemiol, 2003. 24, 86-96.

[9] Millar RJ. Hygiene Highlight: An updated perspective on need stick injuries. Nikos Medicals. April, 2008.

[10] Centers for Disease Control \& Prevention (CDC). Medicine Net.com -Medicine Dictionary. August, 2007.

[11] Radowicka A, Kochmanski M, Zochowski R J. Rare case of asystolic cardiac arrest after administration of xylocaine. Kardiol Pol. 1981. 24, 237-242.

[12] Gilbert T B. Cardiac arrest from inadvertent overdose of lidocaine hydrochloride through an arterial pressure line flush apparatus. Anesth Analg. 2001. 93, 1534-1536.

[13] Wilburn S Q \& Eijkemans G. Preventing Needle stick Injuries among Healthcare Workers: A WHO-ICN Collaboration. International Journal of Occupational and Environmental Health, 2004. 10, 451-456.

[14] National Institute for Occupational Safety and Health. NIOSH. Preventing Needle stick Injuries in Health Care Settings, 2004.

[15] Wilburn N S \& Eijkemans G. Protecting Health Workers from occupational exposure to HIV, hepatitis and other bloodborne pathogens; from research to practice. African Newsletter on occupational Health and Safety, 2007. 17, 34.

[16] Mahfouz E, Mossalam F, Abdel-Rahman S, Abood S, Abdelwahab S. Assessment of NSIs and related knowledge among HCWs participating in an infection control training program at Minia University Hospital. Jan, 2007.

[17] Rakesh S, Mehta H, Manish F, Sunil N, Bhavesh N. Knowledge and awareness regarding NSIs among HCWs in tertiary care hospital in Ahmed Abad, Gujarat. National Journal of Community Medicine. 2010. Vol. 1, Issue 2.

[18] Centers for Disease Control \& Prevention. Blood borne infectious diseases: HIV/AIDS, Hepatitis B and Hepatitis C. July, 2014.

[19] Mulder K. Nadelstich verletzungen-Der bagatellisierte „Massenunfall “. Dtsch Arztebl, 2005. 102, 558-61.

[20] Diprose P, Deakin C \& Smedley J. Ignorance of postexposure prophylaxis guidelines following HIV needlestick injury may increase the risk of seroconversion. Br J Anaesth, 2000.84, 767-70.

[21] Chalupka S, Markkanen, P K, Galligan C J \& Quinn M M. Needle stick and sharps injury prevention: are we reaching our goals? AAACN Viewpoint, 2008. 30, 1.

[22] Parantainen A, Verbeek J H, Lavoie M C \& Pahwa M. Blunt versus sharp suture needles for preventing percutaneous exposure incidents in surgical staff. Cochrane Database Syst Rev, 2011, 11.

[23] Jagger J. Occupational exposure to blood borne pathogens: epidemiology and prevention. Prevention and Control of Nosocomial Infection, 2003. 430-466.

[24] Shah S M, Merchant A T \& Dosman J A. Percutaneous injury among dental professionals in Washington State. BMC Public Health, 2006. 6, 269. 
[25] Sabine W, René G, Holger F. Risk of needle stick injuries. From an Occupational Medicine and Virological Viewpoint. Dtsch Arztebl 2007; 104(45): A 3102-7.

[26] Ikram K, Kaleem Siddiqui H, Maqbool S, Altaf M \& Khan S. Frequency of Needle Stick Injury among Dental Students and Dentists of Karachi. 2015.

[27] El-Houfey A S \& A K. Occupational Exposure to Blood and Body Fluids among Nursing and Dental Students at Internship Year in Assiut City. 2013.

[28] Zafar A, Aslam N, Nasir N, Meraj R \& Mehraj V. Knowledge, attitudes and practices of health care workers regarding needle stick injuries at a tertiary care hospital in Pakistan. J Pak Med Assoc, 2008. 58, 57-60.

[29] Kumar N, Sharma P \& Jain S. Needle stick injuries during fine needle aspiration procedure. Frequency, causes and knowledge, attitude and practice of cytopathologists. Journal of cytology. Indian Academy of Cytologist. 2011.28 (2).

[30] Sharma R, Rasania S, Verma A \& Singh S. Study of prevalence and response to Needle Stick Injuries among Health Care Workers in a Tertiary Care Hospital in Delhi, India. Indian Journal of Community Medicine: Official Publication of Indian Association of Preventive \& Social Medicine, 2010. 35, 74-77.

[31] Hanafi M I, Mohamed A M, Kassem M S \& Shawki M. Needlestick injuries among health care workers of University of Alexandria Hospitals. East Mediterr Health J, 2011. 17, 26-35.

[32] Afridi A, Kumar A \& Sayani R. Needle stick injuries--risk and preventive factors: a study among health care workers in tertiary care hospitals in Pakistan. Glob J Health Sci, 2013. 5, 85-92.

[33] Saleikar S, Motghare D D, Kulkarni M S \& Vaz F S. Study of needle stick injuries among health care workers at a tertiary care hospital. Indian J Public Health, 2010. 54, 18-20.

[34] Mungure E K, Gakonyo J M, Mamdani Z \& Butt F. Awareness and experience of needle stick injuries among dental students at the University of Nairobi, Dental Hospital. East Afr Med J, 2010. 87, 211-4.

[35] Lee L K \& Hassim I N. Implication of the prevalence of needlestick injuries in a general hospital in Malaysia and its risk in clinical practice. Environmental Health and Preventive Medicine, 2005. $10,33-41$.

[36] Waqar S H, Ul Siraj M, Razzaq Z, Malik Z I \& Zahid M A. Knowledge, attitude and practices about needle stick injuries in healthcare workers. Pakistan Journal of Medical Research, 2011. 50, 111.

*Corresponding author.

E-mail address: Mohamed.salim@ ishik.edu.iq 